This item was submitted to Loughborough's Research Repository by the author.

Items in Figshare are protected by copyright, with all rights reserved, unless otherwise indicated.

\title{
Combining business process and failure modelling to increase yield in electronics manufacturing
}

PLEASE CITE THE PUBLISHED VERSION

http://dx.doi.org/10.1243/09544054JEM1794

\section{PUBLISHER}

Sage (@ the authors)

\section{VERSION}

SMUR (Submitted Manuscript Under Review)

\section{PUBLISHER STATEMENT}

This work is made available according to the conditions of the Creative Commons Attribution-NonCommercialNoDerivatives 4.0 International (CC BY-NC-ND 4.0) licence. Full details of this licence are available at: https://creativecommons.org/licenses/by-nc-nd/4.0/

\section{LICENCE}

CC BY-NC-ND 4.0

\section{REPOSITORY RECORD}

Segura-Velandia, Diana M., Paul P. Conway, Radmehr P. Monfared, and Andrew A. West. 2019. "Combining Business Process and Failure Modelling to Increase Yield in Electronics Manufacturing”. figshare. https://hdl.handle.net/2134/22149. 


\title{
Combining business process and failure modelling to increase yield in electronics manufacturing
}

\author{
Segura Velandia, D.M., Monfared R.P., Conway P. P., West A.A. \\ Mechanical and Manufacturing Engineering, Loughborough University, Loughborough, UK
}

\section{ABSTRACT}

The prediction and capturing of defects in low volume assembly of electronics is a technical challenge that is a pre-requisite for design for manufacturing (DfM) and business process improvement (BPI) to increase first time yields and reduce production costs. Failures at the component-level (component defects) and system-level (such as defects in design and manufacturing) have not been incorporated in combined prediction models. BPI efforts should have predictive capability while supporting flexible production and changes in business models. This research was aimed at integration of enterprise modelling (EM) and failure models (FM) to support business decision-making by predicting system-level defects. An enhanced business modelling approach which provides a set of accessible failure models at a given business process level is presented in this article. This model-driven approach allows the evaluation of product and process performance and hence feedback to design and manufacturing activities hence improving first time yield and product quality. A case in low volume high complexity electronics assembly industry shows how the approach leverages standard modelling techniques and facilitates the understanding of the causes of poor manufacturing performance using a set of surface mount technology (SMT) process failure models. A prototype application tool was developed and tested in a collaborator site to evaluate the integration of business process models with the execution entities, such as software tools, business database and simulation engines. The proposed concept was tested for the defect data collection and prediction in the described case study.

Keywords: business process improvement; business process modelling; cause and effect modelling; electronics assembly; yield

\section{INTRODUCTION}

The current highly competitive electronics manufacturing market demands delivering high-quality products with lower cost to their customers in a shorter time. The ever changing customer demand in this industry has created a dynamic nature for the electronics manufacturing market, and therefore, agility to change products rapidly, optimise resources, increase efficiency and redefine business goals are essential elements of an enterprise long-term success and survival.

According to Hubenthal [1] a competitive electronics manufacturer needs to create value through: innovation, improving manufacturing processes, adopting new technologies, adopting customer oriented business models, reducing cost and being agile to changes.

Much research has been carried out to provide solutions to the above issues, in particular to improve agility and reduce production costs. To improve agility, change in the business/organisation model is required with possible need for enhancing the hardware/software infrastructure. To reduce production cost many aspects of an enterprise could have influential roles. One of the most basic and logical aspects is the reduction on product waste and manufacturing defects.

Research work documented in this article focuses on efforts to improve agility in electronics manufacturing businesses through developing flexible business process models and relating them to information technology (IT), failure models, knowledge base (KB) integration and re-engineering approaches. The proposed approach to improve agility has been experimented in an industrial environment at 
various product life cycle phases. In particular, it has been tested in control engineering to reduce product defects through the identification and prediction of defects' causes.

The proposed approach has been implemented in a UK based electronics company to assess effectiveness on the agility of the manufacturing systems and to measure its impact on reducing product waste. An associated application tool was developed to enable implementing the proposed approach within the collaborator's site and to evaluate the proposed concept in an industrial scale.

\section{RESEARCH CHALLENGES}

The creation of agile and flexible systems that can be adapted to meet the ever changing business needs, not only requires proper use of information technology (IT), but the integration of cause and effect models to current process improvement (PI) approaches such as six sigma, business process modelling (BPM) and reengineering (BPR) and benchmarking, to truly provide expected business values. Responding effectively to changes is also known to be difficult technically and financially from both business and IT perspectives.

From the IT point of view, there have been numerous advancements in specific business domain applications e.g. customer relationship management (CRP) and enterprise resource planning (ERP) systems $[2,3]$. Although ERP systems typically integrate most business transaction data in a central data depository, they are often not suitable for data analysis and decision support processes. Therefore, organisations are struggling to query these large data repository systems and are unable to integrate other information links across all business areas to obtain fast and accurate data analyses for decision making [4]. This is, however, not an easy undertake due to the lack of application of efficient engineering processes and, to some extent, the effective use of appropriate hardware and software.

From the business point of view, the poor visibility of "what" changes, the uncertain causes for these changes, the lack of requirements definitions, difficult traceability of processes and defects, and the poor reuse of lessons learnt make business decisions more complex. Furthermore, representing change into defined business problems and requirements is difficult; hence, implementing supporting systems and software that facilitate changes are often ignored.

The domain under investigation in this paper is low volume complex electronics manufacturing. A particular focus is on the UK's electronics low volume market, which has migrated towards supplying low volume solutions to a global market. This market covers the complete spectrum of product complexity from simple innovative monitoring circuits to complex aircraft engine management systems.

Product and production volume variety in this domain typically requires a substantial amount of manual works (i.e. design modifications, system set ups, soldering special components, rework, inspection and defect capturing). This type of production results in time consuming design and manufacturing setup processes and a poor first time yield on complex assemblies. The reasons for these problems are believed to be the result of a number of issues including:

(i) lack of a formalised approach to capture and understand processes' knowledge,

(ii) lack of knowledge concerning the implications of design features on manufacturing performance, 
(iii) defects generated during the manufacturing flow and associated monitoring/ inspection problems,

(iv) lack of in-process performance monitoring and analysis.

\section{PROPOSED SOLUTION}

The electronics manufacturing sector in the UK was studied as part of this research. In order to understand the business structure, processes, information and resources in this sector, the enterprise modelling (EM) approach [5] was adopted. EM enables representing the current and future enterprise organisation in a logical manner and facilitates identifying phases at product life cycle in which lack or incorrect information or resources can potentially cause operational bottlenecks. EM also assists integrating various information sources available within an organisation to the business processes.

Furthermore, to monitor and capture the sources of the product defects, their relationship with the overall enterprise processes were investigated. In order to understand the impact of the defects generated during the manufacturing flow, failure models were integrated to the overall enterprise model to relate failures to the processes at various production life cycles. Based on enterprise and failure models discrete event simulation was used to assist evaluating and optimising the design and manufacturing flow. This is to provide better integration of EM with the product and process knowledge available at enterprise-wide level (typically in form of various IT sources) and minimise product defects.

In addition, it is understood that a long-term success and survival of electronics manufacturers require the integration of cause and effect models, to relate quantitatively a number of process variables. By integrating these models to data contained in production information models, it is possible to validate these models and understand their scope and applicability in production. This integration in turn supports more accurate performance evaluation and predictive capability.

The business process improvement approach developed is aimed at (i) reducing lifecycle costs, (ii) reducing new product introduction timescales, (iii) increasing reliability and (iv) increasing the quality of future designs. The approach proposed in this work was demonstrated and tested in a UK-based contract electronics manufacturer. Further funding has been secured in order to establish the complete integration across the entire supply chain of the studied domain.

\section{LITERATURE REVIEW}

Most of the existing technical knowledge in manufacturing domains has been encoded in the form of Ishikawa diagrams and design rules such as "As the level of $\mathrm{Y}$ decreases, the probability of $\mathrm{Z}$ increases". Rules of this type have been used in order to detect and prevent product failure. However, due to the increasing complexity of design-for-X (DfX) (where $x$ can be yield, reliability, manufacturability, quality) analyses, the use of these rules has proven to be challenging. As design rules grow larger, designers are moving from rule-based inspection of design (for both product and process) to DfX anchored in process cause and effect models, throughout the flow. 
The absence of cause and effect or failure model-driven DfX enabling tools is impacting business decisions and the efficient adoption of emerging technologies. The cause and effect model-based approach has been envisaged to be a solution for design rule-based analyses. For example, in the semiconductor domain, the development of nano-scale chips consists of hundreds of geometric design rules. A $90 \mathrm{~nm}$ chip has around 650 rules for the manufacture process and exponential increases are projected as designers move toward $65 \mathrm{~nm}[6]$.

The cause of failure and its impact on a product's performance (i.e. yield, reliability, quality) has been the focus of study of much research across in the electronics industry. Product failure has been accurately modelled and is mostly understood at the physical level via computational models (e.g. mechanical, thermal) for semiconductors [7] and printed circuit board (PCB) manufacturing and assembly [8,9]. These models are usually limited in scope, developed at specific process steps (e.g. reflow) and sometimes product specific so that the results obtained differ from product to product.

In the semiconductor industry, approaches such as Technology Computer-Aided Design (TCAD) have been the subject of intensive research for the last decade [10, 11]. Using this approach, the physical configuration of integrated circuit devices to related device properties are linked to the physics of behaviour models that support circuit design [12]. In this research the TCAD approach is translated to printed circuit board (PCB) manufacturing and assembly.

Similarly to TCAD, our aim is to study how to bring together the physical configuration of a printed circuit assembly (PCA), related board and device properties and physics of failure process models to enable agile support of PCB manufacturing and assembly under a systems engineering approach.

\subsection{Existing Research on Failure Modelling within Enterprise Modelling Framework}

Only a few researchers have reported such a system engineering approach that combines business process and failure modelling to increase yield and business improvement. Kuo [13] reported on an approach that aims to integrate Coloured Time Petri nets (CTPN) models of a system to Statistical Process Control (SPC) data, process failure, Failure Modes and Effects Analysis (FMEA), and fault diagnosis to simulate and control complex product mixes and flexible manufacturing routes. The proposed integration is done in such way that the models are constructed in terms of CTPN so that information can be exchanged directly.

The use of historical production data has been key to support electronics manufacturing and assembly process improvement. Historical production data has been used to induce defect rules or correlate assembly yield to PCA design or manufacturing parameters. Several researchers have reported regression models generated from shop floor data to match the patterns in design and process parameters with assembly yield [14] and to create or update PCA design rules [15]. Data have been also used in the development of a defect prediction and control system for SMT assembly both for high volume, (currently limited to solderability defects) by employing a neuro-fuzzy tool kit, FuzzyTECH $[16,17]$ and low volume, coded in eXtensible Markup Language (XML) [18] to obtain quality metrics [19] and detect defects that necessitate rework operation for fine pitch SMT laser soldering [18]. These tools, however, have not been implemented under an EM framework. 
Kumar [20] proposed a methodology combining both data-driven and physics of failure models for fault diagnosis and life prediction applicable to circuit assemblies and electronic products [20]. Although this methodology is used in a wider area of prognosis and health management [21], the significance of this approach lies in the integration of data-driven and physics of failure models that consider actual operational and environmental loading conditions.

Newnes et al [22] described an approach using historical data and process modelling using the IDEF0 approach [23] for the optimisation of yield in electronic assembly and manufacturing [24] supported by design of experiments (DOE) and response surface (RS) optimisation techniques. They only reported a PCB manufacture yield improvement of $13 \%$.

Data exchange standards have facilitated the integration of various modelling approaches. Efforts have been made in the last decade to develop product data representation and exchange standards throughout the life cycle of a product (e.g. STEP, ISO 10303). Knowledge-based systems benefit from this type of standards to overcome the current difficulties in visualising, gathering and integrating information throughout a product's life cycle both inside and outside a company [25]. In addition, tool manufacturers could provide neutral and shared platforms to facilitate the adoption of neutral data exchange formats.

"Plug and play" factory enabling technologies (e.g. XML, internet) are being used commonly to overcome these issues to support generic connections between equipment from multiple vendors [26]. In order to accomplish this type of integration, the Institute for Interconnecting and Packaging Electronic Circuits (IPC) has developed a broad set of document type definitions (or data transfer standards) using XML for electronics manufacturing, identified as IPC-2510 series [27-29]. It is anticipated that the adoption of these standards will facilitate the application of knowledge-based tools in real-time applications.

\section{RESEARCH APPROACH}

The literature review has shown that there are a number of research efforts to provide industry with tools to support decision making in electronic assembly and manufacturing. However, there are a few studies on frameworks offering an integrated solution that does not depend on extensive time consuming manual data input. Also, previous work lacks an approach to determining detailed industrial requirements i.e. there has been little study of the processes (business, management, design and manufacturing) within organisations that may impact defect opportunity, its monitoring and its control.

A holistic view of an organisation may provide insight into "what" aspects and "how" they may be changed [30]. Furthermore, the overall effect of specific changes may be enabled through the entire lifecycle of the manufacturing system through an integrated monitoring and simulation environment. An EM approach can be used to support the activity of modelling (i.e. govern the requirements) of any aspect of an organisation [31]. The use of EM techniques is key to determine formalised requirement definitions [32] and obtain abstract modelling views of the enterprise in order to design and implement information systems and modules that could comprise an "industrial strength" knowledge-based tool. The information models within 
the EM can enable integration to shop floor IT systems containing real-time production data and customer information (e.g. bill of materials (BOM), CAD drawings).

Based on the reviewed literature as well as discussion with industrial partners, it becomes clear that there are no sufficiently integrated methods for assisting organisations to estimate reliably production capabilities and predict product failures as new board designs are introduced onto existing production lines. Furthermore, there is no conclusive research to describe: (i) the appropriate methods and tools to integrate and deploy both business and physics of failure process models for producing and supporting process improvements, and (ii) determining how the use of failure models can result in supporting a business need.

The approach presented in this paper employs a process oriented modelling architecture i.e. CIMOSA [31] to (i) describe enterprise functionality through representing process flow, (ii) identify specific information and resources and (iii) specify organisational aspects of the enterprise operations. The adoption of the process modelling approach enables definition of requirements engineering on both business and IT perspectives. On the business perspective, process modelling (i) enables the visibility of an organisation's changes, (ii) represents changes in a structured manner, (iii) facilitates definition and gathering of requirements. On the IT perspective, it could potentially reduce complexity to support specific business needs via the use of formalised knowledge requirements definition and information modelling.

\section{THE ROLE OF FAILURE MODELS IN BUSINESS PROCESS IMPROVEMENT IN LOW ELECTRONICS MANUFACTURING AND ASSEMBLY}

The development of failure models is inherently a cross-disciplinary science since models (e.g. theoretical, empirical, heuristic). The integration of accurate and valid failure models for low volume and high variety of production of complex products is not trivial. Firstly, a low volume production does not generate enough data to validate the models in order to have immediate feedback to design and manufacture activities. Secondly, failure models exist for a varieties of assemblies, electronics components and solder joints and its integration as one quantitative model is difficult. In addition, the quantification of solder joint failure models is a challenging process as it depends on the availability of accurate geometry of the electronics components packages. In this research only a selection of failure models for the electronics assembly boards were studied, focusing on models that allow predicting the most common causes of electronics assembly defects i.e. those defects generated in the three SMT processes i.e. printing, placement and reflow [33].

Figure 1 depicts a high level view of the proposed approach to integrate enterprise model with the other knowledge base abstraction and IT based applications within the enterprise. The proposed approach, composed of (i) modelling, (ii) knowledge base and IT integration, (iii) business reengineering and (iv) functional software modules for defect data capture, simulation and prediction, leverages the EM approach in order to capture stakeholder requirements and support IT requirements (e.g. design of the logical and physical database). As shown in Figure 1, each business process can be related to an enterprise activity failure model. Each failure model can be either a physics of failure, empiric or heuristic model. These models are implemented in the function view for each business process model in order to derive metrics for 
improvement analyses. The major components of the integration approach and how they are interconnected and applied to the enterprise businesses are explained in the following sections.

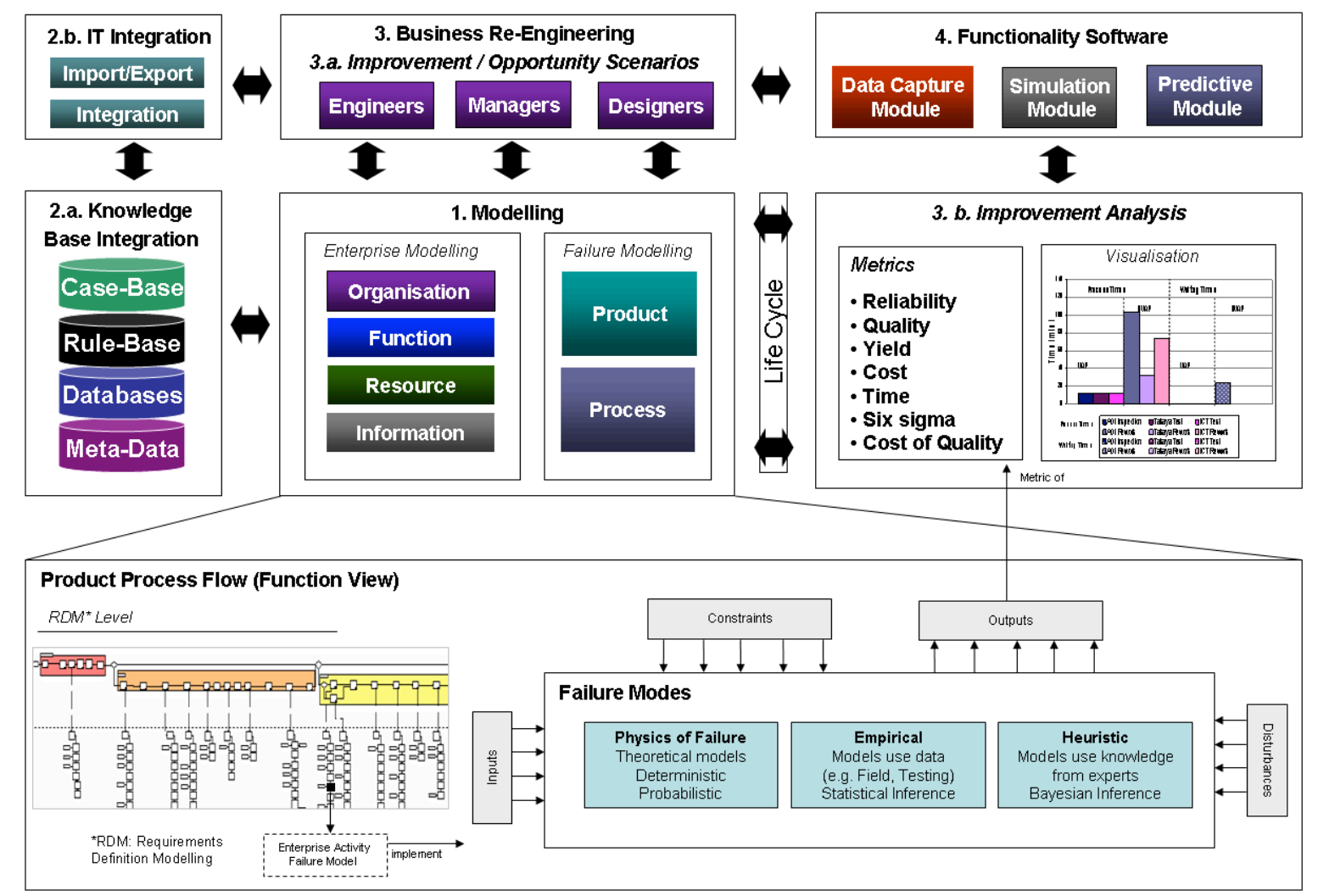

Figure 1. Model-driven approach for business improvement

\subsection{Modelling}

\subsubsection{Enterprise Modelling}

Enterprise modelling is chosen as a suitable business and process-modelling framework. The adopted EM approach in this research is based on application of graphical representation method developed in Loughborough University [34] for business and engineering processes in compliance with CIMOSA architecture, and customised for industrial applications. Using enterprise models a detailed view of the assembly process is obtained. Data from assembly processes of real world industrial case are used to construct the model in order to represent the enterprise and their relationships. Thus, assembly processes (such as surface mount placement, printing, reflow, testing) can be sufficiently understood, modelled, and selectively used for any specific business context. The modelling activity starts with the requirements definition modelling level with a subset of the real world entities, and gradually grows at each genericity level for a chosen modelling view. Standard business domains are identified and decomposed into the subprocesses. A library for various models and their abstractions (known as partial models) are developed, and variations from the existing models are included (known as particular models). 


\subsubsection{Failure Modelling}

Integrating with the developed EM, failure models enable the understanding of cause-and-effect relationships that govern processes by, for example, relating quantitatively a number of process variables. In low volume electronics manufacturing and assembly, several type of failure models have been proposed in the literature [35]. These failure models are described at various product levels e.g. final product level, system, module, unit, and component. A model of solder joint rework [36] implemented as part of this research is shown by Figure 2 as an example in electronics manufacturing sector.

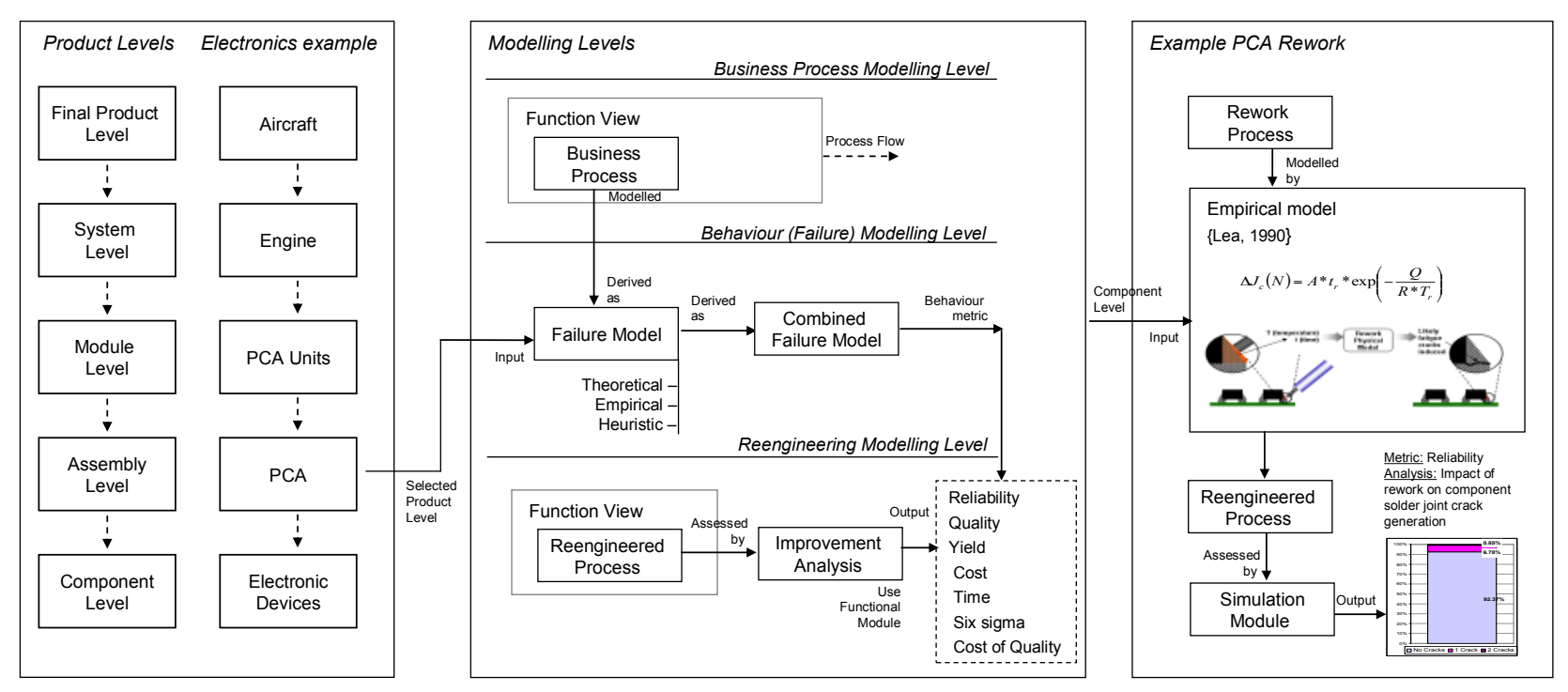

Figure 2. Failure Models relationship for a chosen Business Model at a Product Level.

At a given product level, there can be a range of failure models (e.g. theoretical, empirical, numerical) for a given business process (or enterprise activity in the function view of an enterprise model). These product failure models are combined as part of reengineering techniques in order to understand the impact of defects that could cause product failure. The failure models facilitate obtaining quality, yield, time, cost or reliability of product. For example, previous work by the authors [37] describes the integration of a physical model of rework [36] to a manufacturing model and its execution via a simulation engine. This rework component model enables the quantitative prediction of the number of visible cracks in a solder joint caused by a number of thermal excursions at a certain temperature (see Figure 2). The results of the simulation, in terms of the impact of the manufacturing defects in a particular product in terms of time, cost, quality and reliability are interpreted in the form of charts and tables. A domain specific failure model library was created by extensive literature search, experimentation and computing simulation depending on an organisation's resources.

\subsection{IT and Knowledge Base Integration}

The knowledge base (KB) (e.g. data, rules, cases) needs to be integrated to support the functionality described by the EM. The integration of the KB onto the developed process model is through specification of the information view of the developed process model [34], which under the CIMOSA architecture four perspectives including function, information, organisation and resource views are obtained. While EM 
describes accurately the behaviour and the functionality of the enterprise, a link to the production data and knowledge (e.g. behaviour rules) is required to complement the model. Such link as suggested in Figure 1 can be achieved through the integration of company databases with data repository system such as defect (e.g. Automated Optical Inspection (AOI), and functional test files) and production information (e.g. CAD files, scheduling files).

An expert's experience includes a wide range of information and knowledge that typically has many forms and is commonly referred to as knowledge base. The knowledge base in this paper consists of design rules and other domain knowledge such as cases acquired over a period of time that describe how a particular problem is solved. Other domain knowledge refers to a collection of many different kinds of knowledge such as descriptive definitions of specific terms, description of objects and their relationships to each other, criteria of making decisions (e.g. rules, heuristic knowledge), etc. Formally, the combination of different knowledge representations to benefit synergistically from them, normally results in a coherent "knowledge base".

A more traditional approach is to extract rules from data correlations and encode as "IF-THEN-ELSE" rules. Rules have been derived from companies design for manufacturing (DfM) documents that describe the best practices and requirements that must be included in the design at the conceptual stages to ensure the manufacturability of the product and known cause and effect relationships (i.e. as shown in Figure 3). Design for manufacture guidelines detail manufacturing process capabilities and describe manufacturing preferences and limitations of a particular process. These documents are used in companies as a manufacturing checklist, or as an essential guideline for designers during the DfM stage. Cause and effect relationships are not usually formalised in any document and remain the "expert's" heuristic knowledge i.e. loosely defined knowledge or rules acquired by experience. This knowledge, however, has been elicited and represented in the form of Ishikawa diagrams such as the one shown in Figure 3. From these diagrams, cause and effect rules have been developed by assigning measurable (data-driven) attributes to the rules.

The developed rule-base comprises the knowledge that is specific to the domain of application (i.e. electronics defect analysis). Thus, the rule-based reasoning system can determine the probability of occurrence of a particular defect in a given package type by matching the current PCA design features against both: (i) the DfM rules and the (ii) cause-effect rules can also be used as a screening activity prior to the PCA process determining whether a PCA should be scrutinised further or what level of inspection should be given to the assembly.

Guided by an expert, software can be used to determine relationships between defects and associated parameters likely to have caused the problem. For example, to measure the trend of causes for a particular defect (i.e. bridging - where adjacent legs of a component or PCA tracks are shorted together), an expert can interrogate at the data to see whether the defect has been historically associated with design issues (e.g. solder resist dimensions, stencil thickness, PCB finish, pad orientation), machine settings (e.g. humidity related, temperature related, stencil cleaning frequency, stencil cleaning efficiency) or materials and tooling (e.g. squeegee type, board support, board support, paste type, stencil manufacturing method) as shown diagrammatically in the Ishikawa diagram [38] in Figure 3. 


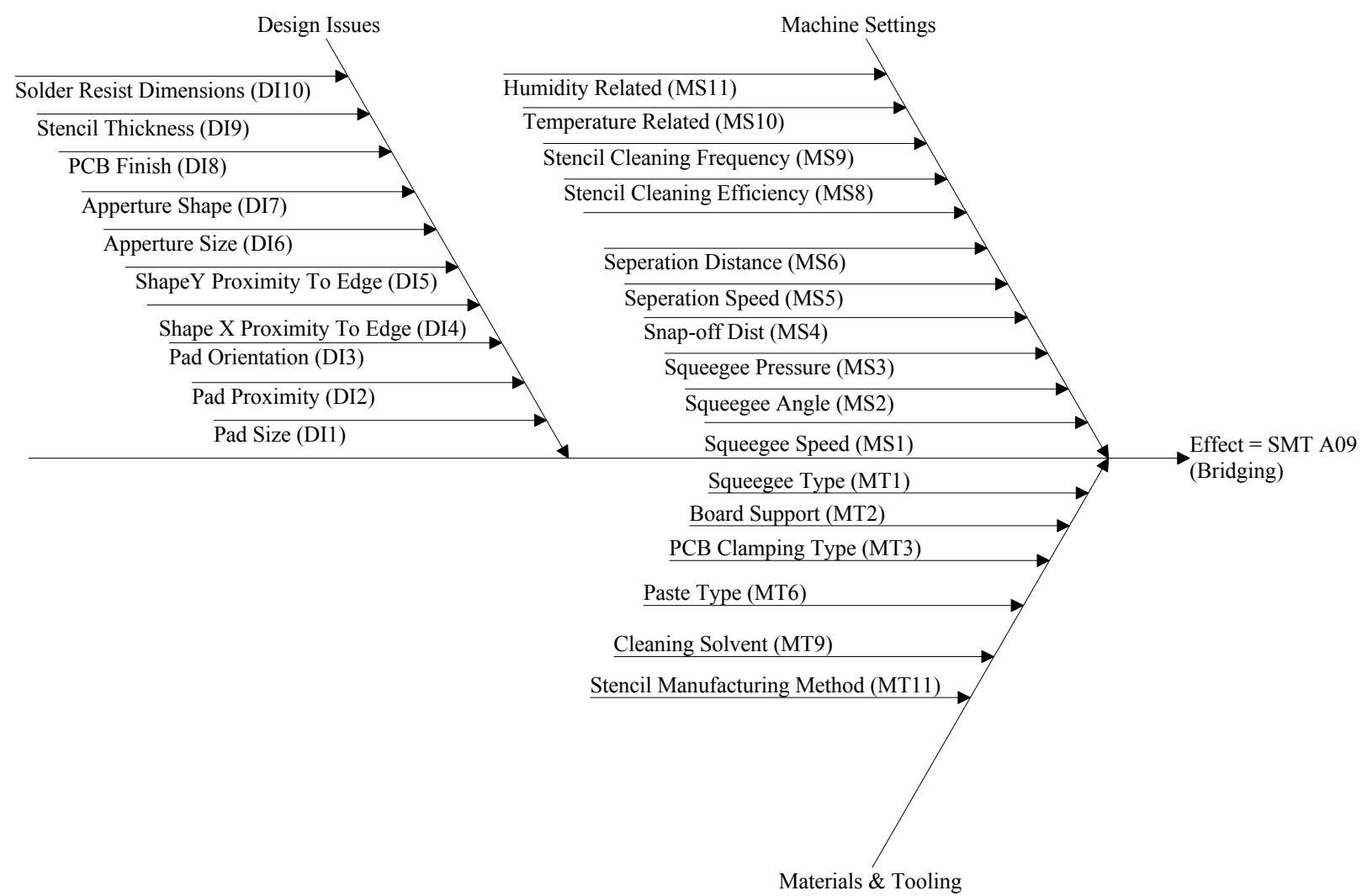

Figure 3. Ishikawa diagram for the bridging defect effect

However, it has been noted that the important information about an assembly that enables defects to be traced to root cause(s) can be stored in several places and with different conventions, syntaxes and semantics. Therefore, root-cause analysis based on these data using data-mining techniques involves a large data integration effort. These and other issues in KB integration are out of the scope of this paper.

The main goal of the database integration, is to allow a user to treat as a single database multiple databases using different data models, query languages or schemas. To achieve this integration, a mechanism that allow the user to avoid dealing with multiples DBs individually and the formulation of multiple queries in different DB languages is required. Using the information view of enterprise models (refer to Figure 4), information constructs (e.g. Information object) and their relationships can be obtained. These constructs are expressed in terms of an implementation language (e.g. UML and SQL) to produce an enterprise logical data model.

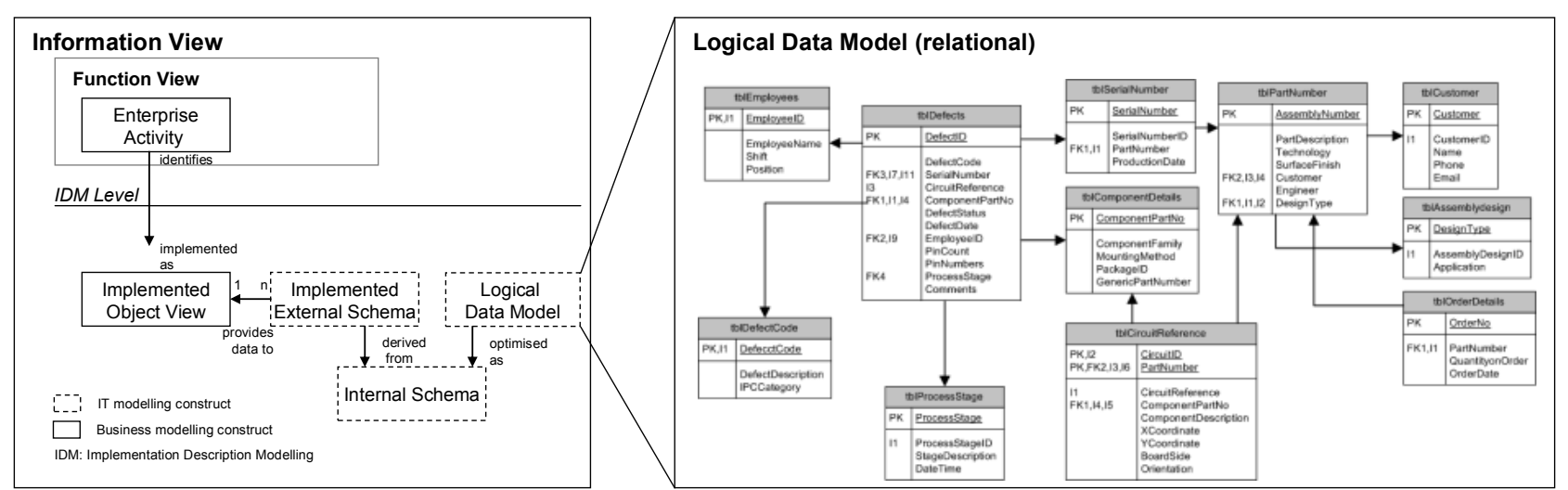

Figure 4. Logical data model derived from an enterprise model's information view 
This logical data model is then integrated to the company's DBs via Open Data Base Connectivity (ODBC) links. These connection links contain the information needed to allow a computer user to access the information stored in multiple DBs. An example of the company's ERP system database integration to the developed enterprise logical model is shown in Figure 5. Each of the information objects of the schema (e.g. Sales, production, IT- Data Management, Quality, Human Resources) are connected to a source (in this case, specific ERP DB tables). Additionally, an implemented external schema (or SQL view) shows how the software system uses data elements, both internally through adding, updating, deleting and externally through querying. These data elements can then be organised into user schemas, which in turn can be related to the overall system's conceptual schema.

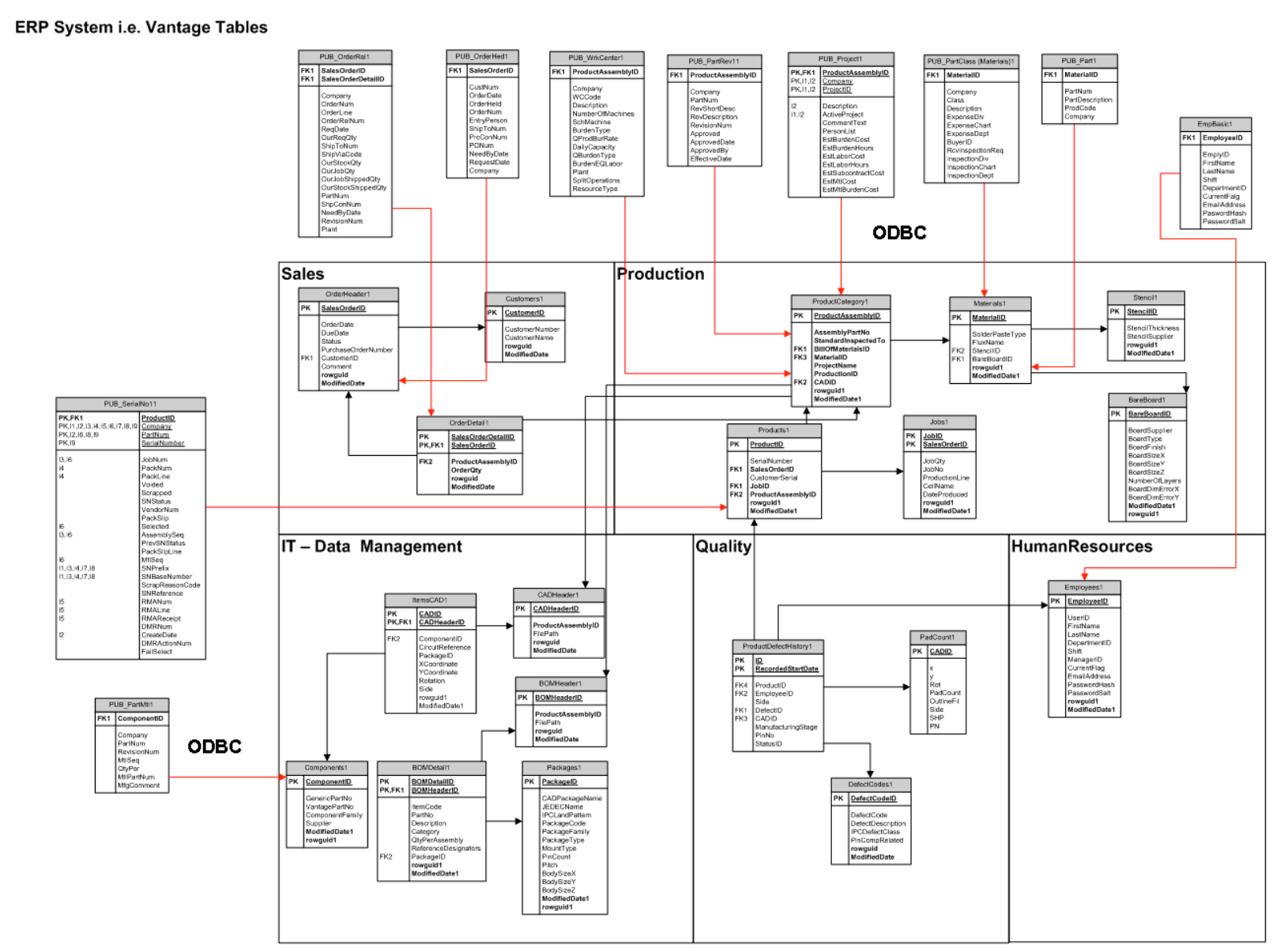

Figure 5. ERP DB integration via ODBC links

\section{INDUSTRIAL APPLICATION}

The described approach was implemented in industry as part of the UK funded projects CLOVES (Complex LOw Volume Electronic Systems) and DISCOVER (Design and Simulation of Complex Low Volume Electronics Production). The projects' industrial partners are part of the UK's aircraft electronic subsystem design and manufacture domain. 
A set of tools were developed as proof-of-concept in accordance with the functionality described by the process models. The prototype tools were aimed at (i) improving the quality in assembling electronic PCBs by increasing possibility to detect product failures at early stages of the production life cycle, (ii) enabling the prediction of defects using failure models for PCB assembly processes, (iii) enabling the simulation of production capability and product quality reliability and (iv) capturing the product defects in a more efficient manner and collecting/categorising the defect data to build up and enhance product behaviour and the knowledge base.

The functionality of the tool was developed based on the collaborators' requirements and include the following modules: (i) defect data capture, (ii) quality data analysis, (e.g. yield prediction and six sigma) (iii) case-based reasoning (i.e. prediction using cause and effect lessons learnt), (iv) defect prediction using physical models, (v) simulation (e.g. cost, time, solder joint reliability estimation, and (vi) support of legacy data. In this paper only the "Defect Data Capture" functional module is discussed. This is the basis for all the decision support modules as it provides the defects data underlying the enterprise quality process models. The other domains are being described in on going publications.

\subsection{Functionality to Support Quality - A Case Study}

Identifying defective components in a typical electronics manufacturing system is a time consuming process and requires highly skilled operators, in particular for complex and safety critical boards, which was the case in the industrial site targeted for implementation of this research. The efficiency of this process depends on the accuracy of the CAD model describing the board/components design and the application tools that enables presenting the components graphically and capturing the defects in a systematic manner.

The end-users (inspectors and quality engineers) requirements for the Defect Data Capture module were to (i) phase out paper-based defect data recording by (ii) generating a schematic for the CAD representation of the assembly that users can interact graphically to (iii) select and enter failed component data directly to the database. The developed application allows users to record defects' details such as the date, time, processing stage when the defect happened; component, package style, serial, batch, and customer's order number where it happened. Other data, outside of the scope of this paper, includes recording "why" the defect happened and the consequences of not finding the defect (e.g. an estimation of rework operation, scrapping the component, scrapping the board) at early stages. These data constitutes part of the investigation into the failure root cause analyses using case-based reasoning. Recording the defect data enables generating standard quality industry metrics (e.g. IPC 9261 and six sigma) in a short time to provide, for example, timely customer feedback, and to analyse possible defect correlations with expert's chosen parameters (e.g. component's cardinal position, package style and other assembly features).

\subsection{Reengineering of Board Assembly Inspection Processes}

Manufacturing and assembly business processes of the above case study were modelled in compliance with CIMOSA modelling architecture, as shown partially in Figure 6. 


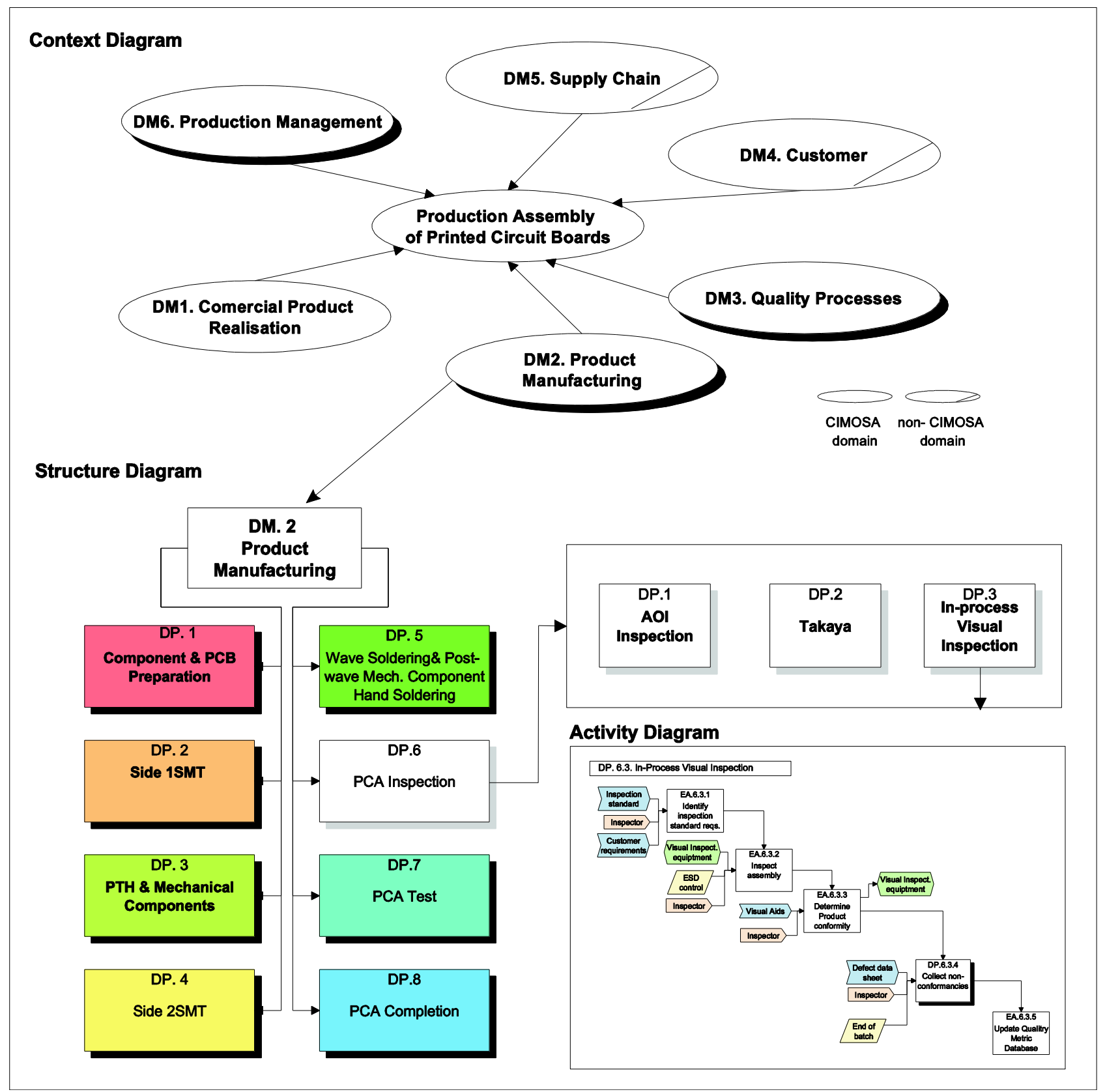

Figure 6. Context diagrams showing a breakdown of the domains analysed. DM. Domain, DP: Domain Process.

Initially, a context diagram was developed to show the main domains analysed with the end user organisation, such us DM1 Commercial product realisation, DM2 Product Manufacturing, DM3 Quality Processes, DM6 Production Management. From these domains, particular interest in this paper is given to the inspection processes were the focus aiming to improve defect data capture.

The business processes analysed for the Product Manufacturing domain (DM2) are non-deterministic process i.e. they have poor-defined control flow logic with a high degree of manual intervention. In order to deal with semi-structured and non-structured activities and processes, various types of behavioural rules were added to the activity and process workflow as also suggested by Berio [39]. For DM2, these behavioural rules were extracted from the company's Manufacturing Pack, which contains all the necessary customer documentation, and company's generated Manufacturing Instructions to build a product to customer requirements. The Manufacturing Instructions document indicates the standard operations for each 
build reference along with the appropriate company procedure and any "special instructions" for the build and testing of the product.

The PCA inspection domain process (DP.6) consists of various processes including automatic optical inspection (AOI), functional test (Takaya) and in-line visual inspection process (DP. 6.3). The DP 6.3 is also non-deterministic as it does not have well defined control flow logic. Inspection processes lead to assembly non-conformances (e.g. unsoldered joints, board scratch, missing components). These defects and their rework are usually recorded for quality control purposes. In Figure 7, the recording of non-conformances (BP.6.3.1) is shown for both the "as-is" view showing an entirely a manual process and the "to-be" view requiring automation. The enterprise model shown in Figure 7 provides the activities that determine the tasks and the flow of information to be supported by the developed software module. 


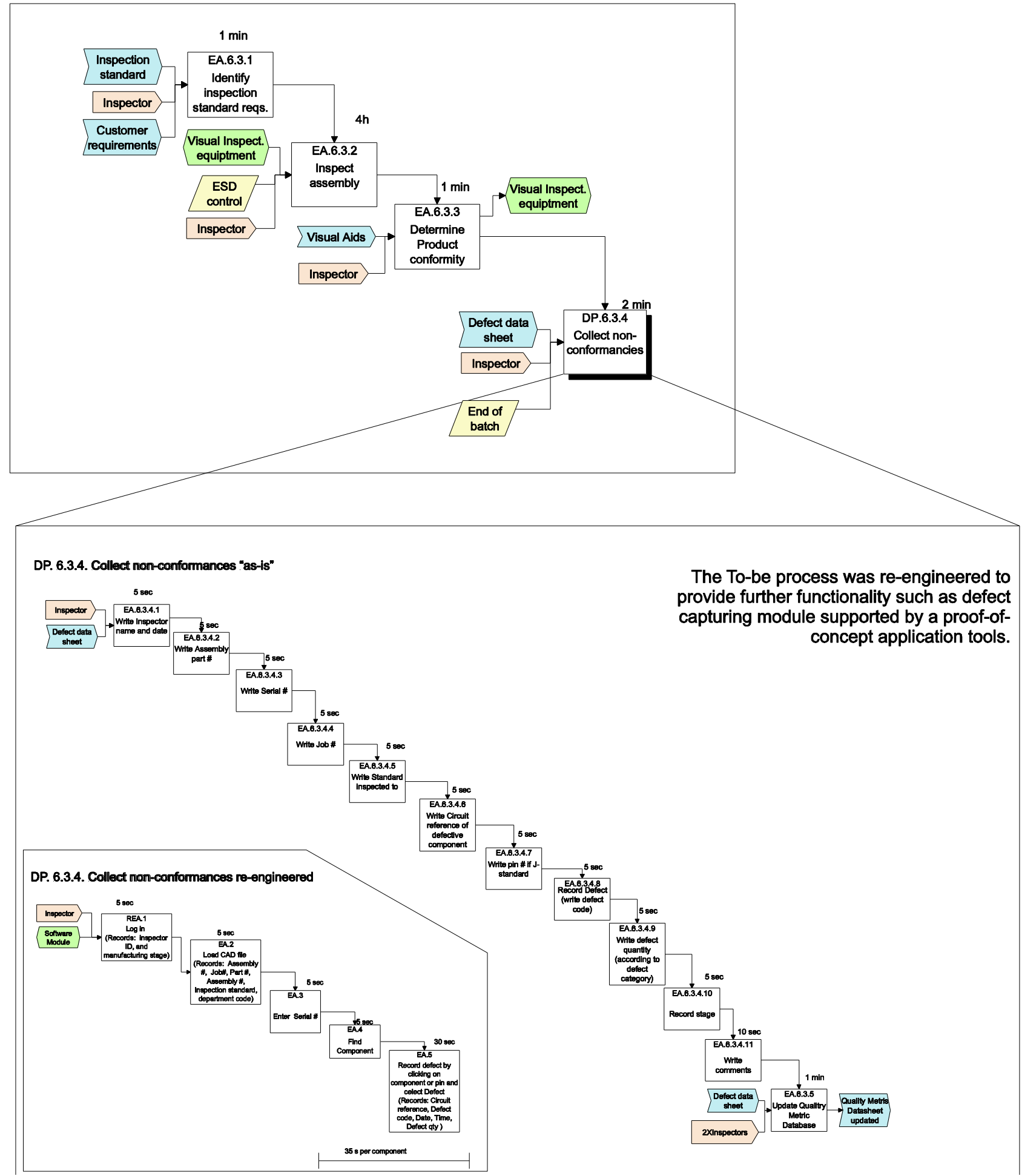

Figure 7. Details of domain process DP6.3. (part of 3rd level decomposition) and details of DP6.3.4 (part of $4{ }^{\text {th }}$ level decomposition). Insert figure: Re-engineered model of DP6.3.4. DP: Domain Process; DP1.x Business Process; EA: Enterprise Activity

The main processes to meet the end-user requirements described above involved the integration of CAD and the development of a defects' database integrating it with other company's data repositories (e.g. integration to enterprise resource (ERP) system [40]). 


\subsection{Surface Mount Process Failure Models}

Failure cause models and associated design rules and effects data were extrapolated from the collaborator information systems and formulated into developed physical models for surface mount primary processes identified in figure 6. Previous publications from the authors describe details on the method used to integrate these physical models [35]. For each surface mount process (printing, placement and reflow), a failure or combination of failure models was obtained to model the cause and effects for solder bridges, chip flotation; tomb-stoning and mid-chip solder balls.

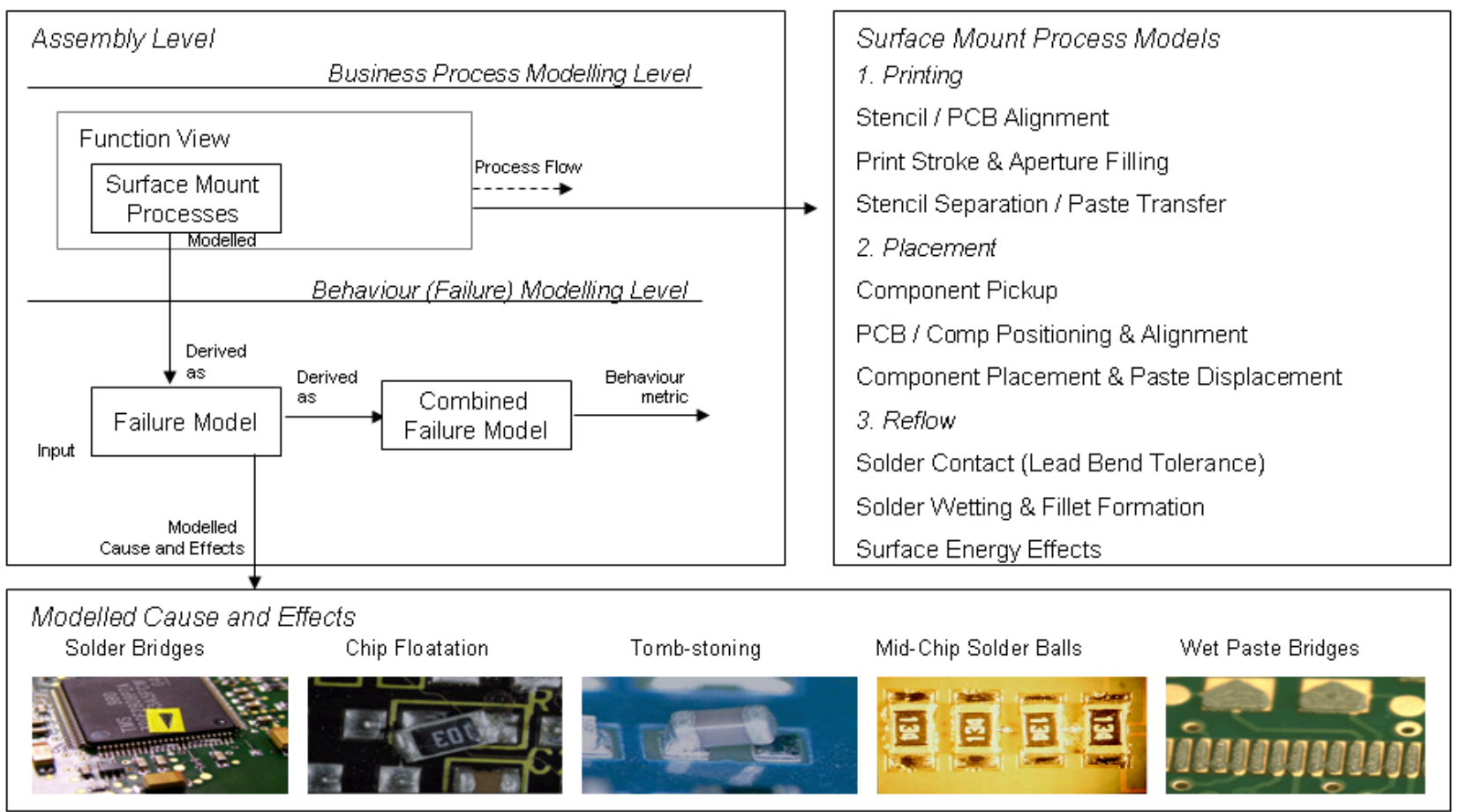

Figure 8. Failure Models for the automated PCA assembly processes i.e. SMT processes

In the process of finding the root-cause of defects, historical data can be used to induce useful information such as relationships or patterns. Guided by an expert, software can be used to determine relationships between defects and associated parameters likely to have caused the problem. For example, to measure the trend of causes for a particular defect (i.e. bridging - where adjacent legs of a component or PCA tracks are shorted together), an expert can interrogate at the data to see whether the defect has been historically associated with design issues (e.g. solder resist dimensions, stencil thickness, PCB finish, pad orientation), machine settings (e.g. humidity related, temperature related, stencil cleaning frequency, stencil cleaning efficiency) or materials and tooling (e.g. squeegee type, board support, board support, paste type, stencil manufacturing method).

\subsection{Integration of CAD Data}

The integration of CAD data onto the EM's information view and subsequently to the prototype application tool was necessary to meet the end user requirements i.e. recreate a CAD visualisation that represents the board assembly, enable operators to interact directly at component level and allows to collect defect data. It 
was also necessary to obtain the information required for the quality engineers from the CAD data to enable failure analysis, instantiation of process physical models, and improvement analyses. Data required to be linked to the components' CAD circuit reference includes package style, dimensions, pitch, pin count, coordinates, component's generic name, rotation, side on the board, supplier, and type.

In order to implement a graphical user interface to obtain the required assembly defect and CAD data, various CAD data structure (e.g. ODB++ and FATF format files) were examined. The case study was conducted in a contract electronics manufacturer (CEM), with customer CAD files received in various industrial formats. These CAD files are edited at various assembly stages to generate placement files or generate testing files (for example for flying probe and bed of nails testing). Some of the CAD formats that were translated into the company's main CAD format is shown in Table 1.

Table 1. Some of the CAD formats that are currently translated to the native CAD file used by the collaborators.
\begin{tabular}{|l|l|l|l|}
\hline ACADEMI & DEDALE & MENTOR Expedition & TOPCAD \\
ACCEL & DIF & ORCAD (DOS) & ULTI_BRD \\
CADENCE & DOCICA & ORCAD (WINDOWS) & VERIBEST \\
CADES-G & GENCAD & PADS & VCAD \\
CADNETIX & HP & PCAD & VISULA \\
CADSTAR & IBM-V4 & PRISMA & VALOR \\
CALAY & IBM-V5 & PROTEL & VUTRAX \\
CASE VANGUARD & INTERGRAPH & RECAD & ZUKEN \\
CV-THEDA & MENTOR & SCICARDS & \\
DDE-ECAD & BoardStation & & \\
\hline
\end{tabular}

Despite supporting various CAD formats, there are no comprehensive standards to produce accurate "translated" formats (e.g. FAT) from customers' CAD models. It is still the case that every CAD provider develops their own translating software and provides customers with their internal definitions on how to integrate to it. These translated formats are not free from errors. The errors are not always identified by users and hence it is common to find translated CAD files with inadequate component and package information. These issues directly affect the accuracy of database records that depends on the translated files and have an impact on data-driven analyses (e.g. simulation, prediction, root cause analysis, data mining) depending on those databases.

Furthermore, following implementation of the developed prototype application within the collaborator site, it was found out that the lack of consistency (and standardisation) within various existing CAD formats results in a significant number of errors and omissions in identifying component defects. This is an important issue in reliability of highly safety critical products, as a missing component (due to the CAD errors) will not be identified, tested, controlled or traced back.

\subsection{Development of a Defects' Database}

Using the information models associated with the enterprise model, the logical and physical database and the software systems' architecture were developed as partially shown in Figure 9. The model shown interlinks to the processes defined by EM and integrates to the ERP system through the developed prototype application as shown above in Figure 5.

The defect attributes for the defect schema arise from various sources including: (i) information stored in dedicated production and quality engineering databases and (ii) hardcopies of defect data sheets (historical 
records, experimental knowledge of engineers and operators). The relevant data fields include, for example, the assembly code, serial number, customer, inspection stage, inspector identification, defect code and circuit reference of the defective component. Some partners also record the number of damaged leads and their location. Other information of importance to enable defects to be traced to the root cause(s) are not stored in one location but in several databases, hardcopied folders and engineers notes. As a result root-cause analysis based on these data is extremely difficult and time consuming. For this reason a generic database has been developed that can include all of the relevant attributes listed above with supplementary information, for example, concerning the package style of the component, position on the board (i.e. $\mathrm{x}, \mathrm{y}, \mathrm{z}$ ) coordinates) which have proven vital to support root-cause analyses. Some of the attributes of the defect database are summarised in Table 2.

Table 2. A sample list of the attributes included within a typical electronics manufacturing defect database

\begin{tabular}{|c|c|c|}
\hline Attribute & Name & Definition \\
\hline \multicolumn{3}{|l|}{ Assembly related } \\
\hline Customer ID & intCustomerID & Organisation that buys the PCA \\
\hline Serial Number & strSerialNumber & Unique PCA identifier \\
\hline Assembly Code & strAssemblyCode & PCA design number identifier \\
\hline Assembly Design Type & strAssemblyType & $\begin{array}{l}\text { Type of PCA, whether is a prototype, mature product, internal, } \\
\text { external }\end{array}$ \\
\hline Assembly Contract Type & strContractType & $\begin{array}{l}\text { Standard to which the PCA is inspected to i.e. J-standard, IPC } \\
610-A\end{array}$ \\
\hline Assembly Quantity & strAssemblyQuantity & Number of boards assembled \\
\hline PCA Width & strPCAWidth & PCA Width \\
\hline PCA Length & strPCALength & PCA Length \\
\hline PCA Datum & strPCADatumXY & $\begin{array}{l}\text { Localisation of the PCA where the components coordinates are } \\
\text { relative to }\end{array}$ \\
\hline \multicolumn{3}{|l|}{ Component related } \\
\hline Reference Designator & strReferenceDesignator & Alphanumeric component label \\
\hline Top Side / Bottom Side & strSide & Side on the board where the component is \\
\hline Package Style & strPackageStyle & A text string designating the electrical package \\
\hline Component Coordinates in $\mathrm{X}$ & $\begin{array}{l}\text { intComponentCoordinat } \\
\text { eX }\end{array}$ & Location where the component appears on the board in $\mathrm{x}$ \\
\hline Component Coordinates in $\mathrm{Y}$ & $\begin{array}{l}\text { intComponentCoordinat } \\
\text { eY }\end{array}$ & Location where the component appears on the board in $y$ \\
\hline Component Rotation & intComponentRotation & Rotation of the component on the board \\
\hline \multicolumn{3}{|l|}{ Defect Related } \\
\hline Defect Code & strDefectCode & Description of a manufacturing defect \\
\hline Process Stage & strProcessStage & Stage at what the defect was found \\
\hline PinNo & intPinNo & Defective Pin/Lead \\
\hline Defect Date \& Time & dteDateTime & Data when the defect was found \\
\hline Employee ID & intEmployeeID & Person responsible for entering the defect on the database \\
\hline Quantity & intQuantity & Number of the same defect that were found \\
\hline
\end{tabular}




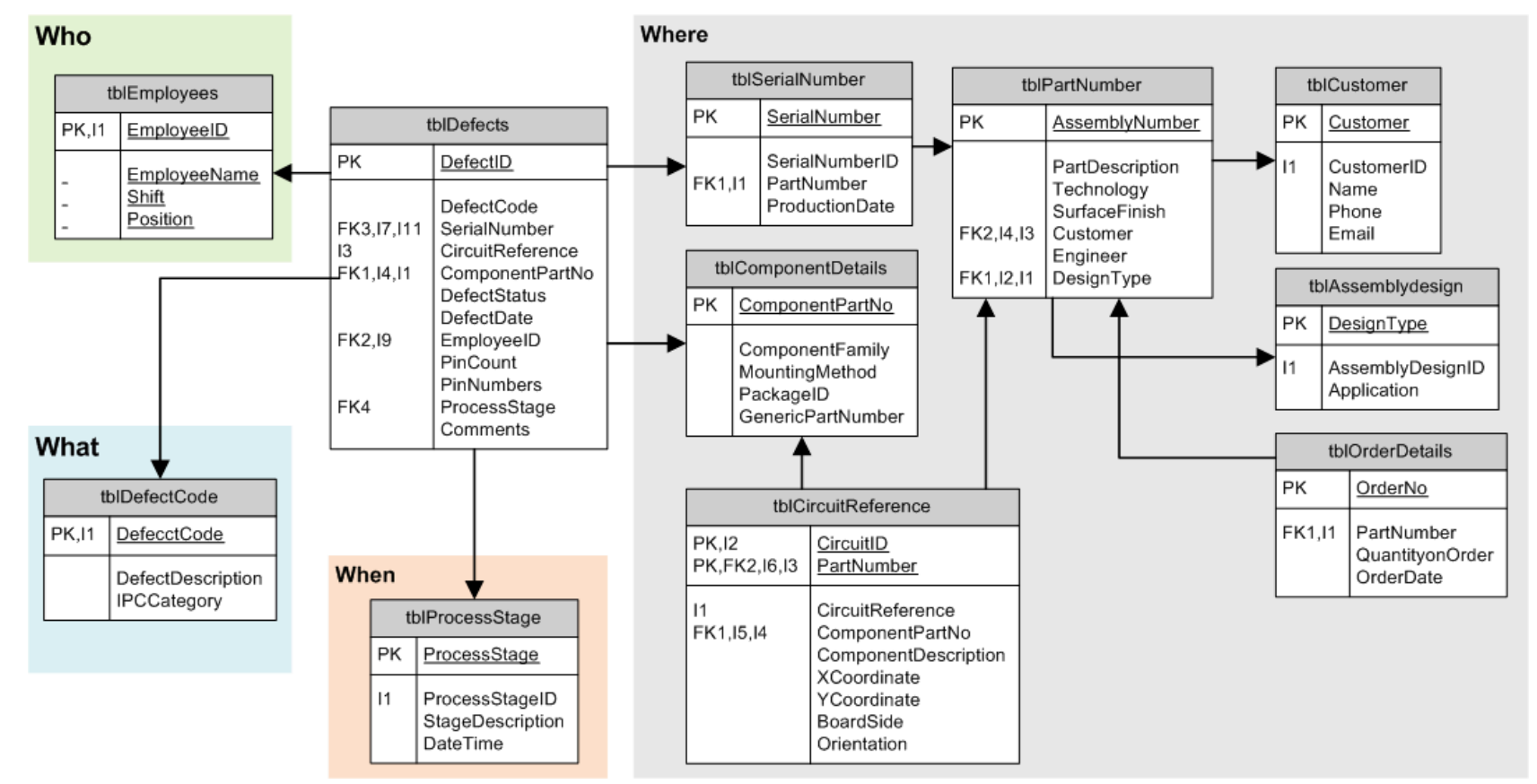

Figure 9. Simplified database schema detailing end-user defect data capture requirements

\subsection{Defect Data Collection Tool}

Improving the quality and performance of the defect data collection process were the main concern of the collaborator's quality engineers. Such improvement was envisaged to be possible through reengineering of the inspection process. Therefore a prototype software application was developed as a proof-of-concept and was implemented within the collaborator's site to examine the concept of change capability and the reengineering process within an industrial case study.

This tool is designed to import a number of industrially standard electronics CAD formats and provide an interactive assembly visualisation for fast and accurate access to the defected components (see Figure 10). The defect collection tool is structured based on the process model developed for the partner. This application is linked to the information view of the developed CIMOSA process model to structure data presentation according to the main company data repository. This includes product data related to the quality control and the process data related to the inspection processes. The data structure is automatically formed within the application via importing the information view of the process model as an XML file onto the application tool. This allows configuring and customising the software application based on changes in business process models. The application data structure is then populated based on the SQL scripts imported from defect database (see Figure 9) and the shop floor intermediate production database. The shop floor database will update regularly the central information repository system, in this case an ERP system.

The prototype tool also visualises graphically the components and packages on a board with detail level of pins and pads of each component. This feature allows the end user not only identify the defected components, but also specify the pin/pad number that causes the defect. The user can then associate the defects to a certain type of common defects that can help statistical and predictive analyses of the defects.

Enhanced visualisation of the defects and colour coordinating the defects types provides invaluable overview on the products defects as a whole. This feature enables expert quality engineers to conclude 
reasons for defects based on the location of defects on the board and their proximity to a thermal mass (e.g. large components, or lack of thermal flow at part of a board).

At each inspection station user's details, manufacturing stage, and product data are logged on to the intermediate shop floor database. The CAD visualisation activity replaces the need for paper-based printed visual aids. By opening an assembly CAD file, while connected to the database, the Job, which is the production batch number, and assembly part information are loaded and displayed on the screen in the information tab. By selecting a Job, the Assembly Part No, Assembly Revision and Inspection Standard are retrieved from the database. Currently the operator will have to identify the boards, however it is planned to use radio-frequency identification (RFID) tags in PCAs to improve efficiency in product traceability and management. The defect data tool enables the operators to identify defected component rapidly, have a detailed view from the components (including part, pins, pads etc.), and highlight the defected elements, typically pins or pads, and assign particular type of defects to the failed component, as illustrated by Figure 10. The prototype application currently supports five reengineered enterprise activity (REA) of user log in (REA.1 - based on the resource view of the CIMOSA process model), load CAD file (REA.2 - from company's ERP system), enter serial number (REA.3 - manual or automatically based on barcode or RFID tag), find component (REA.4 - rapid recognition of part based on pre-loaded CAD data onto the tool) and record of defect by clicking directly on CAD Pin (REA.5) as partially shown by Figure 10.

To tackle the problem regarding the missing components as a result of non-standard CAD formats, a CAD integrity check engine (CICE) was developed and embedded into the prototype tool. The algorithm used for CICE is based on two business process conditions. If the CAD file provided by customer is associated with a bill of material, the CICE checks the availability of CAD data (from board level down to the pin/pad levels) based on the components identified in the BOM. However, in different circumstances, when only a CAD file is available, The CICE runs multiple integrity checks against components types, parts and pin/pads listed within the CAD file. In this case study, a catalogue of the electronics component was linked to the CICE to compare the integrity of the CAD data with the standard components in the market and identify the insufficient CAD data for each component. Specifying the missing CAD data, the application tool draws a standard product shape in the place of the missing component to indicate extra checks required for the that components. This feature provides extra reliability for the quality control and defect collections when manufacturing safety critical parts. 


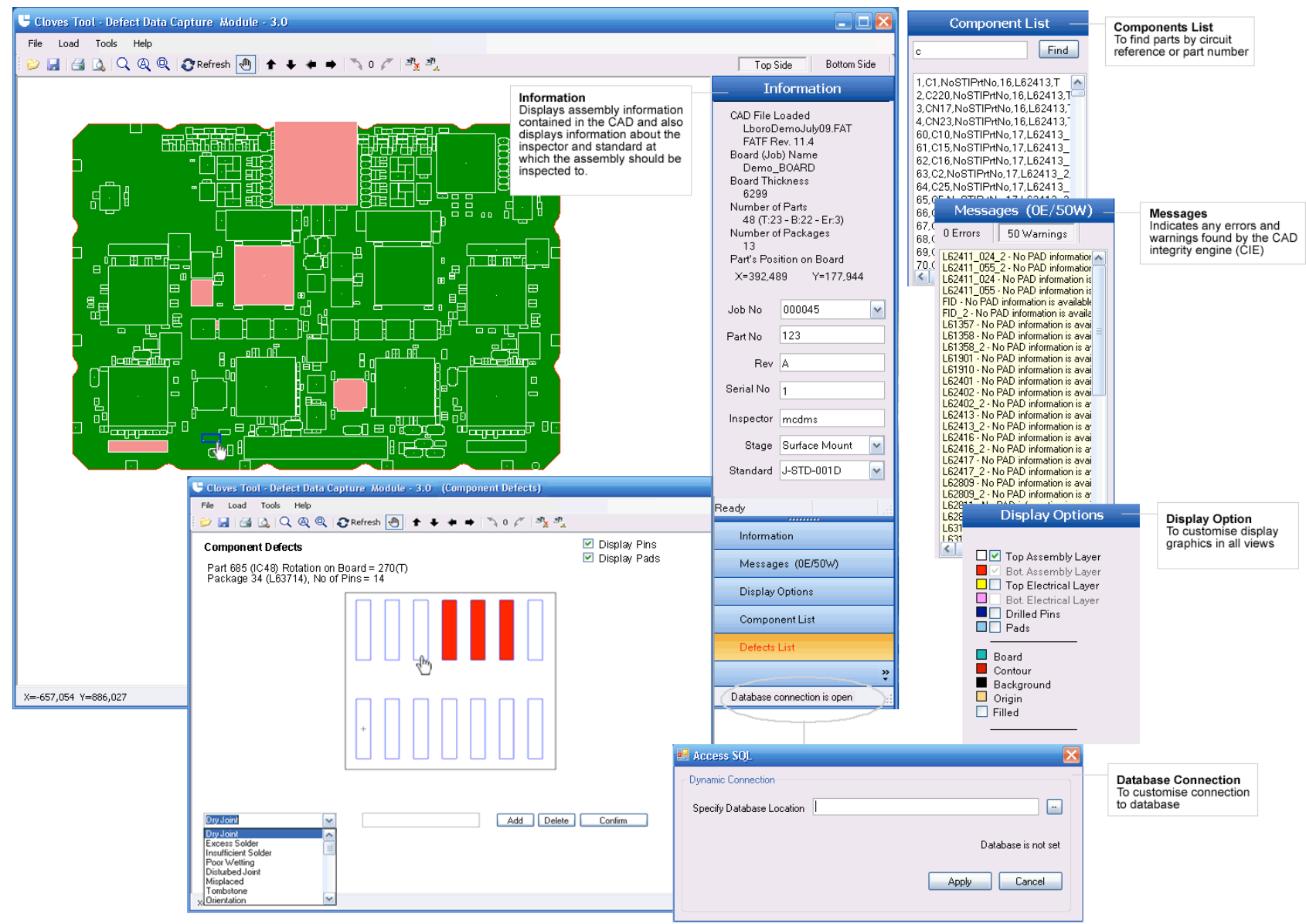

Figure 10. Screen capture of find component and recorded defect

\subsection{Simulation Model}

A simulation module was developed using Arena $^{\mathrm{TM}}$ simulation tool to enable enactment of the process models and simulate quality-based scenarios to provide performance metrics in terms of the domain requirements. In this case study, the simulation model was structured for the domain control and inspection engineering according to the developed process model. The simulation data was imported from shop floor database, which is in turn populated by the prototype application tool described earlier.

The resulting integrated software tool enables complete and accurate assessments of the product defects. The metrics used to perform the evaluation are given in terms of lead-times, manufacturing cost, quality and reliability of products, and the defect percentage. The simulation model generates statistical information based on the real-time defect control data. It also provides predictive information based on the accumulative defect historic data. A physical model for rework has been used for the prediction of component's joint failure as detailed in [37].

The simulation results for the cased study reported in this paper, conclude that changes proposed on the inspection process could lead to 50\% saving in non-value added (NVA) time, 53\% in NVA cost, $25 \%$ in defect repair cost and $75 \%$ in reliability in terms of probable component's joint fatigue cracks [37].

In addition, other aforementioned failure models for the SMT process are being implemented using industry manufacturing models in order to quantify component defects such as solder bridges, tomb-stoning, 
solder balls and chip floating (refer to Figure 8). In the conducted case study, for the SMT printing process, various data are required to execute the simulation and the equations underlying the physical models to predict component defects. Figure 11 shows specific inputs to deploy the combined printing model (this is including models for each of the associated enterprise activities such as stencil and PCB alignment, printing stroke and aperture filling and stencil preparation and paste transfer). These inputs include CAD data to obtain components' body dimensions, stencil thickness, aperture reduction, board dimensional tolerance and stencil thickness.

Preliminary results have allowed suggesting design changes to the stencil aperture in order to reduce manufacturing errors (in form of component defects) to $9 \%$ which in turn is a reduction of $54 \%$ in labour cost as shown in Figure 11.

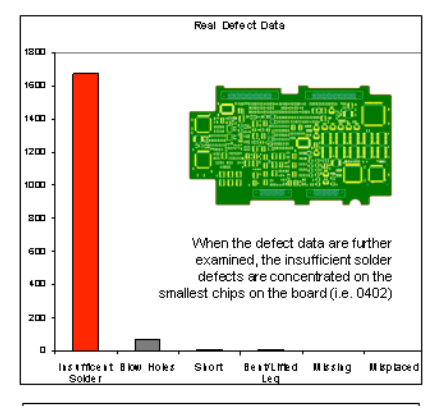

input data (deterministic data)

- CAD and component data

- Stencil thickness $=200 \mu \mathrm{m}$ (with steps in some areas to $150 \mu \mathrm{m})$

- Aperture reduction $=50-70 \mu \mathrm{m}$

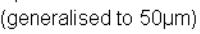

- Board dimensional tolerance $=$ $\pm 0.1 \mathrm{~mm}=0.028 \%$

- $\quad$ Copper thickness $=17.5 \mu \mathrm{m}$
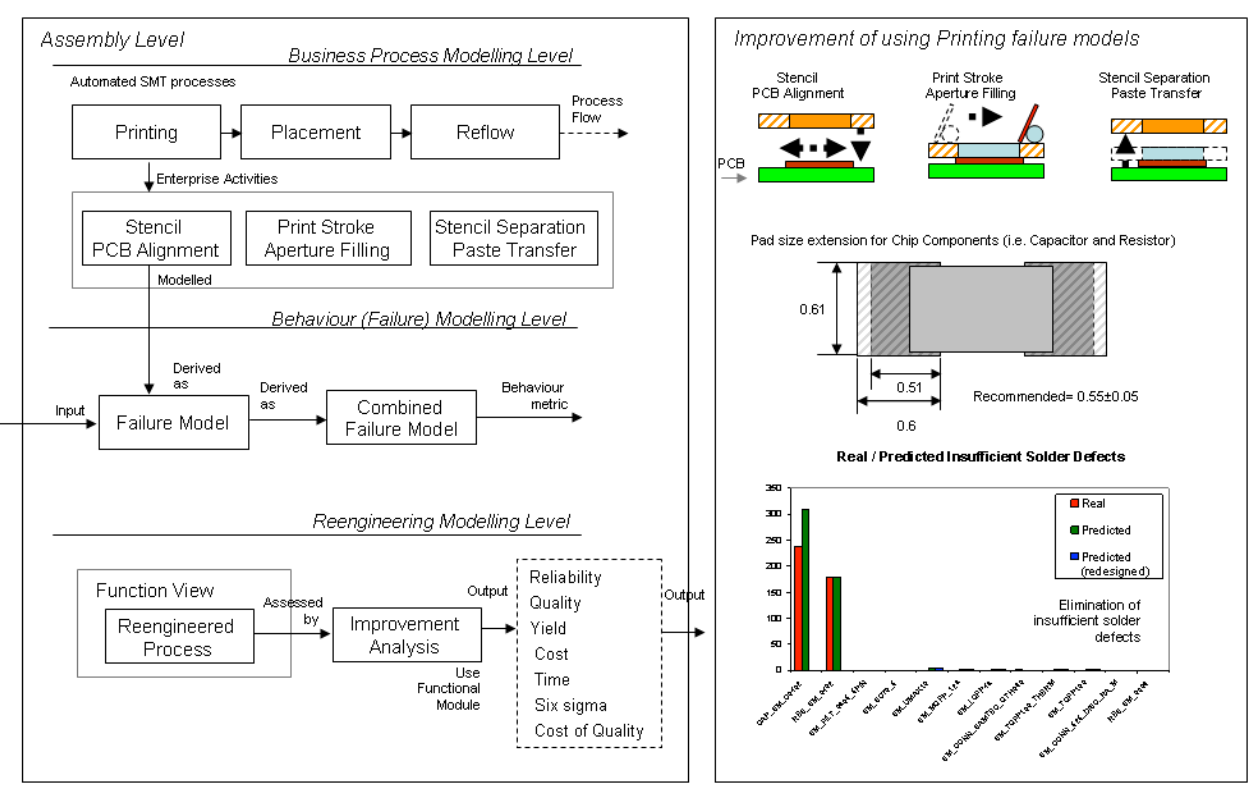

Figure 11. Application of SMT printing combined failure model to predict insufficient solder in 0402 chips

\subsection{Result of the Case Study}

The result of the conducted cases study at the collaborator site was examined and validated by the industrial partners. The results proved the concept of integration of failure models, product CAD design, BOM and data depository systems onto the enterprise model is applicable to an industrial scale.

The initial results of the case study predicts that in the first year of implementing the defect data capture module, the company could potentially save up to $£ 200 \mathrm{k}$ by decreasing the cost of capturing defects, identifying failed assemblies at their early stage of their production phases, and improving product reliability. This was calculated based on a typical production on the collaborator site, including an average of 120 serials (variations of similar board types) assembled per week and 100 defects found in average in each serial. As shown in Figure 5, it takes 2 minutes in average for an inspector to record and update the database per defect per component compared with 35 seconds using the proposed defect data capture module. The timing data was captured from an actual production line at the collaborator site. Therefore for a typical board an inspector would normally take 3 hours to identify and fill in the defects for a serial. In contrast, with the 
defect module, the same process takes 35 second per component plus 15 seconds per serial. This is approximately 6 minutes per serial.

\section{CONCLUSIONS AND FUTURE DIRECTIONS}

The problems associated with the identification and capturing defects in electronics manufacturing boards within a certain UK based industry were investigated.

Modelling approach, prototype application tools, and simulation were used to address the identified problems and to investigate the impact of proposed solutions within an industrial environment.

A detailed enterprise model was developed from the industrial partner's business processes and a failure model was adopted, expanded, and integrated onto the enterprise model. The description of the enterprise model led to the development of a prototype application tool, which is used to identify and capture component and assembly defects. The description of an information view for the enterprise model, in association with the failure model led to development of an information model in compliance with the partner's data repository system. A simulation model was developed based on the system specifications defined by the enterprise model to measure changes on the system performances when using the proposed solution.

The proposed approach successfully integrated CAD design information onto the quality control processes so that enterprise and physical models can be configured for the whole assembly manufacturing life cycle i.e. integrated circuit devices, tracks, and related board properties. The prototype application tool was used at the partner's site in a proof-of-concept scenario. Following an initial successful experiment, a full-scale implementation of the tool is planned to reside as part of the production resources.

Such implementation would provide definitive assessment on the effectiveness of the proposed approach in a real industrial scenario.

Industrial inputs from various electronics manufacturers indicate need for further investigation to provide universally applicable modules that are easily configurable and extensible. Such modules should be able to predict possible defects at the design phase of the electronic boards, in addition to the quality control phase. It is envisaged that further enhancement to the approach required to link business processes to those product and process physical models to provide traceability will eventually help generate yield and quality models.

Additional application development work is required to facilitate the creation and enactment of enterprise models and the instantiation of physical models that allows end users to configure models to obtain improvement analyses. In addition, based on the global nature of the industry, web-enabled capability of the tools is being considered.

A major contribution of this study is the integration of (i) a process oriented model of electronics manufacturing systems (within context of this study) with physical configuration of a PCA (i.e. by using assembly CAD files), (ii) printed circuit board and device properties (e.g. by using material databases) and (iii) physics of failure process models (by using theoretical models already described in the expert literature 
and validated using historical data) in order to enable agile support of PCB manufacturing and assembly under a systems engineering approach.

\section{ACKNOWLEDGEMENTS}

The authors wish to express their gratitude to the industrial collaborators. This work was supported financially by the IeMRC DISCOVER grant, SP/05/01/02 and DTI CLOVES grant, TP/3/DSM/6/I/16333.

\section{REFERENCES}

1. Hubenthal, D. and S. Burr, Thought Leadership Strategy: The New Competitive Strategy for Consumer Electronics Industry Leaders. 2008, Hubenthal Burr Associates. Available from: http://www.TeamHBA.com [Accessed: 10th January 2010]

2. Metaxiotis, K., Exploring the rationales for ERP and knowledge management integration in SMEs. Journal of Enterprise Information Management, 2009. 22(1-2): p. 51-2.

3. Yen, D.C., D.C. Chou, and J. Chang, A synergic analysis for Web-based enterprise resources planning systems. Computer Standards \& Interfaces, 2002. 24(4): p. 337-346.

4. Chou, D.C., BI and ERP integration. Information Management \& Computer Security, 2005. 13(5): p. $340-349$.

5. Vernadat, F., Enterprise Modeling and Integration. First ed. 1996: Chapman and Hall.

6. Lammers, D. and R. Wilson, Heavy rules hold back 90-nm yield, in EE Times. 2005.

7. Plummer, J.D., Process and device modeling. Microelectronics Journal, 1990. 21(2): p. 7-20.

8. Van Steenberge, N., et al., Analytical and finite element models of the thermal behavior for lead-free soldering processes in electronic assembly. Microelectronics Reliability, 2007. 47(2-3): p. 215-222.

9. Sun, W., Study on the board-level SMT assembly and solder joint reliability of different QFN packages. EUROSIME 2007: Thermal, Mechanical and Multi-Physics Simulation and Experiments in Micro-Electronics and Micro-Systems, Proceedings, 2007: p. 344-349.

10.Dutton, R.W., TCAD - Yesterday, Today and Tomorrow. IEICE transactions on electronics., 1999. 82(6): p. 791.

11.Chin, G., A Tool Towards Integration of IC Process, Device, and Circuit Simulation. IEEE journal of solid-state circuits., 1992. 27(3): p. 265-273.

12.Giles, M., TCAD Process/Device Modeling Challenges and Opportunities for the Next Decade. Journal of Computational Electronics, 2004. 3(3-4): p. 177-4.

13.Kuo, C.-H., Control of Automated Manufacturing Systems - Failure Modeling and Process Monitoring for Flexible Manufacturing Systems Using Colored Timed Petri Nets. IEEE transactions on robotics and automation : a publication of the IEEE Robotics and Automation Society., 2000. 16(3): p. 301.

14.Li, Y., R.L. Mahajan, and J. Tong, Design factors and their effect on PCB assembly yield - statistical and neural network predictive models. IEEE/CHMT European International Electronic Manufacturing Technology Symposium, 1993: p. 353361.

15.Joo, Y. and R.R. Barton, Integrated product and process design through feedback of manufacturing experience. Computers and Industrial Engineering, 1995.28(3): p. 561 - 573.

16.Yang, T. and T. Tsai, Modeling and implementation of a neurofuzzy system for surface mount assembly defect prediction and control. IIE Transactions, 2002.34(7): p. 637-646.

17.FuzzyTECH®. 2007, INFORM GmbH.

18.Fidan, I., et al., Internet-based electronics manufacturing troubleshooting tool for surface mount PCB assembly. International Journal of Advanced Manufacturing Technology, 2006. 27(5-6): p. 561-567.

19.Fidan, I., CAPP for electronics manufacturing case study: Fine pitch SMT laser soldering. Journal of Electronic Packaging, 2004. 126(1): p. 173-176.

20.Kumar, S., et al., A Hybrid Prognostics Methodology for Electronic Products. 2008 IEEE International Joint Conference On Neural Networks, 2008. 1-8: p. 3479-3485.

21.Pecht, M.G., Prognostics and Health Management of Electronics. 2008: Wiley-Interscience.

22.Newnes, L.B., A.R. Mileham, and A. Doniavi, A systems approach to electronic assembly optimization. Proceedings of the Institution of Mechanical Engineers B, 2001: p. 1409-1415.

23.Vernadat, F.B., Business process modelling: comparing IDEF3 and CIMOSA. Re-Engineering for Sustainable Industrial Production. Proceedings of the OE/IFIP/IEEE International Conference on Integrated and Sustainable Industrial Production, 1997: p. 307,.

24.Doniavi, A., A systems approach to photolithography process optimization in an electronics manufacturing environment. International journal of production research., 2000. 38: p. 2515-2528.

25.2006-2007 IPC International Technology Roadmap for Electronic Interconnections. Volume 1 Trends and Issues. 2007, IPC.

26.Dugenske, et al., The National Electronics Manufacturing Initiative (NEMI) plug and play factory project. International Journal of Computer Integrated Manufacturing, 2000. 13(3): p. 225-244.

27.Delamer, I.M. and J.L. Martinez Lastra, Quality of service for CAMX middleware. International Journal of Computer Integrated Manufacturing, 2006. 19(8): p. 784-804. 
28.Spera, J., Making Sense of CAMX Initiatives - A new solution improving information availability is allowing manufacturers to distinguish themselves as uniquely efficient in the maturing market. Electronic packaging and production, 2002. 42(11): p. 20.

29.IPC-9261, In-Process DPMO and Estimated Yield for PWAs. IPC, 2002.

30.Weston, R., The importance of holistic model driven manufacturing systems. Proceedings of the Institution of Mechanical Engineers Part B -Journal of Engineering Manufacture, 1998. 212(1): p. 29-44.

31.Vernadat, F.B., Enterprise modeling and integration principles and applications. 1996, London: Chapman \& Hall.

32.Monfared, R.P., Practical Application of Enterprise Modelling. 2003: Wolfson School of Mechanical and Manufacturing Engineering, Loughborough University.

33.Dusek, M. and C. Hunt, A novel measurement technique for stencil printed solder paste. Soldering \& Surface Mount Technology, 2003. 15(2): p. 35-45.

34.Monfared, R.P., Enterprise Modelling: A Component-Based Approach to Design and Construction of Change Capable Manufacturing Cell Control Systems. 1st ed. 2009, Saarbrücken-Germany: VDM Verlag.

35.Wilson, A.R., et al. Characterization of Printed Solder Paste Excess and Bridge Related Defects. in Proceedings of the 2nd Electronics System Integration Technology Conference, ESTC. 2008. Greenwich.

36.Lea, C., The Harmfulness of Re-Working Cosmetically Defective Solder Joints. Soldering \& Surface Technology, 1990(5): p. 4-9.

37.Huertas Quintero, L.A.M., et al., Integrated simulation tool for quality support in low-volume high-complexity electronics manufacturing domain. International Journal of Production Research, 2008(September): p. 1-25.

38.Ishikawa, K., Guide to quality control. Rev. ed. 1982: Asian Productivity Organisation.

39.Berio, G. and F.B. Vernadat, New developments in enterprise modelling using CIMOSA. Computers in Industry, 1999.40(23): p. 99-114.

40.Helo, P., Managing agility and productivity in the electronics industry. Industrial Management \& Data Systems, 2004. 104(7): p. 567-577(11). 